Annales Geophysicae (2003) 21: 1197-1207 (c) European Geosciences Union 2003

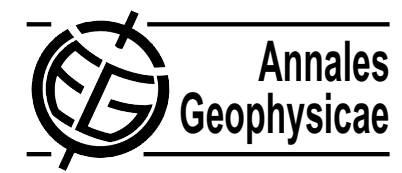

\title{
Diagnostic study of errors in the simulation of tropical continental precipitation in general circulation models
}

\author{
J. Srinivasan \\ Centre for Atmospheric and Oceanic Sciences, Indian Institute of Science, Bangalore, 560012, India
}

Received: 18 July 2002 - Revised: 17 October 2002 - Accepted: 27 October 2002

\begin{abstract}
A simple diagnostic model has been used to identify the parameters that induce large errors in the simulation of tropical precipitation in atmospheric General Circulation models (GCM). The GCM that have been considered are those developed by the National Center for Environmental Prediction (NCEP), the National Center for Atmospheric Research (NCAR) and the Japanese Meteorological Agency (JMA). These models participated in the phase II of the Atmospheric Model Inter-comparison Project (AMIP II) and simulated the climate for the period 1979 to 1995. The root mean-square error in the simulation of precipitation in tropical continents was larger in NCEP and NCAR simulations than in the JMA simulation. The large error in the simulation of precipitation in NCEP was due to errors in the vertical profile of water vapour. The large error in precipitation in NCAR in North Africa was due to an error in net radiation (at the top of the atmosphere). The simple diagnostic model predicts that the moisture converge is a nonlinear function of integrated water vapour. The large error in the interannual variance of rainfall in NCEP over India has been shown to be due to this nonlinearity.
\end{abstract}

Key words. Meteorology and atmospheric dynamics (precipitation; tropical meteorology; convective processes)

\section{Introduction}

During the past 25 years, sophisticated General Circulation Models (GCM) have been used to simulate the seasonal variation of rainfall in the tropics. A major project for systematic comparison of the performance of different Atmospheric General Circulation models was undertaken under the Atmospheric Model Inter-comparison project (AMIP). The objectives of AMIP have been discussed by Gates (1992). The rainfall pattern in the tropics simulated by $30 \mathrm{GCM}$ that participated in the AMIP was compared by Gadgil and Sajjani (1998). They found that most of the models could simulate

Correspondence to: J. Srinivasan (jayes@ caos.iisc.ernet.in) the seasonal variation of precipitation in the African continent but not over the Indian subcontinent. A number of factors could contribute to the poor simulation of monsoon rainfall by some GCM. The simulation of monsoon rainfall in the GCM depends strongly on the manner in which clouds, radiation and surface hydrological processes are represented in these models. Moreover, if one of these processes, say clouds, is parameterized in a different manner, it has an influence on the other processes (such as radiation and surface hydrology). In many GCM small changes in cumulus, radiation or boundary layer parameterization cause large changes in the spatial and temporal variation in rainfall. Gadgil and Sajani (1998) found no simple relationship between the ability of a GCM to simulate accurately the seasonal variation of precipitation and the manner in which the physical processes (such as clouds and radiation) are parameterized in the model. The inherent complexity of a GCM rules out the possibility of identifying any one factor as the cause for the poor simulation of monsoon rainfall. Hence, it is necessary to examine the various factors that determine the accuracy of simulation of tropical rainfall in a GCM. A simple diagnostic model can identify the important parameters that determine the accuracy of the simulation of precipitation. In this paper, a diagnostic model developed by Srinivasan (2001) has been used to identify the factors that contribute to errors in the simulation of tropical rainfall. Since the simple model developed by Srinivasan (2001) is valid over continents only, we focus our attention in this paper on the errors in the simulation of tropical continental rainfall.

Srinivasan (2001) has shown that the observed seasonal variation of precipitation in large tropical continents can be simulated using a simple diagnostic model that is based on energy and moisture balance in a vertical column of the atmosphere. This diagnostic model identifies four parameters that control the seasonal variation of rainfall. The four parameters are evaporation, net radiation at the top of the atmosphere, integrated water vapour, and a new parameter that depends upon the variation of temperature and humidity with height. In this paper we examine the errors in the simulation 
of rainfall in GCM in the terms of the errors in the four parameters identified by the simple diagnostic model.

In Sect. 2, the simple diagnostic model proposed by Srinivasan (2001) is discussed. In Sect. 3, the four parameters identified by the Simple Diagnostic Model (SDM) is used to identify the factors that contribute to large errors in the simulation of precipitation in GCM. Three General Circulation models that participated in the second phase of the Atmospheric Model Inter-comparison Project (AMIP II) have been used. In the AMIP II simulations, the monthly-mean sea surface temperature was specified for the period 19791995. In Sect. 4, we discuss the singular behavior in NCEP when integrated water vapour is high. In Sect. 5, we examine the impact of different kinds of errors on the simulation of rainfall. In Sect. 6, we summarize the results.

\section{Simple diagnostic model}

In the tropics, horizontal gradients of temperature and moisture are weak and hence, their contribution to the energy balance is usually small when compared to the contribution of other terms, such as radiation, latent heat release or vertical gradient of temperature. Neelin and Held (1987) have argued that horizontal advection terms are small in tropical regions. Hence, the integral form of the law of conservation of moist static energy and moisture can be written as (Neelin and Held, 1987)

$$
\begin{aligned}
& \int_{0}^{1} \omega\left[\partial m / \partial p^{*}\right] \partial p^{*}=g\left[F_{B}-F_{T}\right] \\
& \int_{0}^{1} \omega\left[\partial(L q) / \partial p^{*}\right] \partial p^{*}=g[E-P],
\end{aligned}
$$

where

$$
\begin{array}{ll}
\omega & =\text { vertical velocity, } \\
m & =\text { moist static energy }=s+L q, \\
s & =\text { dry static energy, } \\
L & =\text { the latent heat of condensation, } \\
q & =\text { specific humidity, } \\
p^{*} & =p / p_{O}, \\
p & =\text { pressure } \\
p_{O} & =\text { surface pressure, } \\
g & =\text { acceleration due to gravity, } \\
E & =\text { evaporation from the ground, } \\
F_{B} & =\text { sum of radiative, sensible, and evaporative } \\
& \text { heat fluxes at the surface, } \\
F_{T} & =\text { radiative flux at the top of the atmosphere } \\
P & \text { and } \\
P & =\text { precipitation. }
\end{array}
$$

The above two equations can be combined to obtain an expression for precipitation.

$$
[P-E]=\left\{F_{B}-F_{T}\right\} /\{\delta-1\},
$$

where

$\delta=-\left\{\int_{o}^{1} \omega\left[\partial s / \partial p^{*}\right] \partial p^{*}\right\} /\left\{\int_{o}^{1} \omega\left[\partial(L q) / \partial p^{*}\right] \partial p^{*}\right\}$.
Fortelius and Holopainen (1990) have shown that on monthly mean scales the energy stored in the soil in the continents is small and hence, net flux at the bottom of the atmosphere (i.e. $F_{B}$ ) is close to zero. The net flux at the top of the atmosphere $\left(F_{T}\right)$ is purely radiative. This flux is measured by satellites and is known as net radiation at the top of the atmosphere $\left(Q_{\text {net }}\right)$. By definition, $Q_{\text {net }}=-F_{T}$.

Hence, in the tropical continental regions, the above equation can be simplified to

$P=E+Q_{\text {net }} /\{\delta-1\}$.

In the above equation, $P, E$ and $Q_{\text {net }}$ can be expressed in terms of $\mathrm{mm} /$ day or $\mathrm{W} / \mathrm{m}^{2}$. The second term in the righthand side of the above equation represents the moisture convergence. Note that the moisture convergence term has been obtained from the constraints imposed by the moist static energy budget and not from the equations governing the dynamics of the flow. The magnitude of $\delta$ is always greater than 1 and hence the sign of this term is determined by the sign of $Q_{\text {net }}$. In regions of the tropics wherein $Q_{\text {net }}$ is negative, the amount of rainfall is less than evaporation, because the second term on the right-hand side of Eq. (4) is negative. In regions wherein $Q_{\text {net }}$ is positive, the second term is positive and its magnitude is determined by how close $\delta$ is to 1 . Srinivasan (2001) obtained a simple expression for $\delta$ based on the following simple assumptions regarding the variation of vertical velocity, temperature and specific humidity with pressure:

$\omega=4 \omega_{m} p^{*}\left[1-p^{*}\right]$

$T=T_{o}-\Gamma z$

$q=q_{o}\left[p^{*}\right]^{\lambda}$,

where

$$
\begin{array}{ll}
\omega_{m} & =\text { maximum vertical velocity } \\
T_{o} & =\text { surface temperature } \\
\Gamma & =\text { Temperature lapse rate } \\
q_{o} & =\text { surface specific humidity } \\
\lambda & =\text { non-dimensional exponent }
\end{array}
$$

Based on the simple assumptions made above, we obtain the following expression for $\delta$

$$
\begin{aligned}
& \delta=C / P_{w} \\
& C=\left[p_{o}(a-1) \beta(\lambda+2) C_{P} T_{o}\right] /[L g \lambda(\beta+1)(\beta+2)],
\end{aligned}
$$

where

$$
\begin{array}{ll}
a & =g / C_{P} \Gamma \text { (non-dimensional parameter) } \\
\beta & =R \Gamma / g \text { (non-dimensional parameter) } \\
R & =\text { ideal gas constant of air }(J / \mathrm{kg} \mathrm{K}) \\
C_{P} & =\text { specific heat of air at constant pressure }(J / \mathrm{kg} \mathrm{K}) \\
P_{w} & =\text { total water vapour in a vertical column of the } \\
& \text { atmosphere }\left(\mathrm{kg} / \mathrm{m}^{2}\right)
\end{array}
$$

The quantity $\delta$ depends upon a number of parameters. We find from Eqs. (8) and (9) that $\delta$ depends upon surface temperature, surface pressure, temperature lapse rate, integrated 


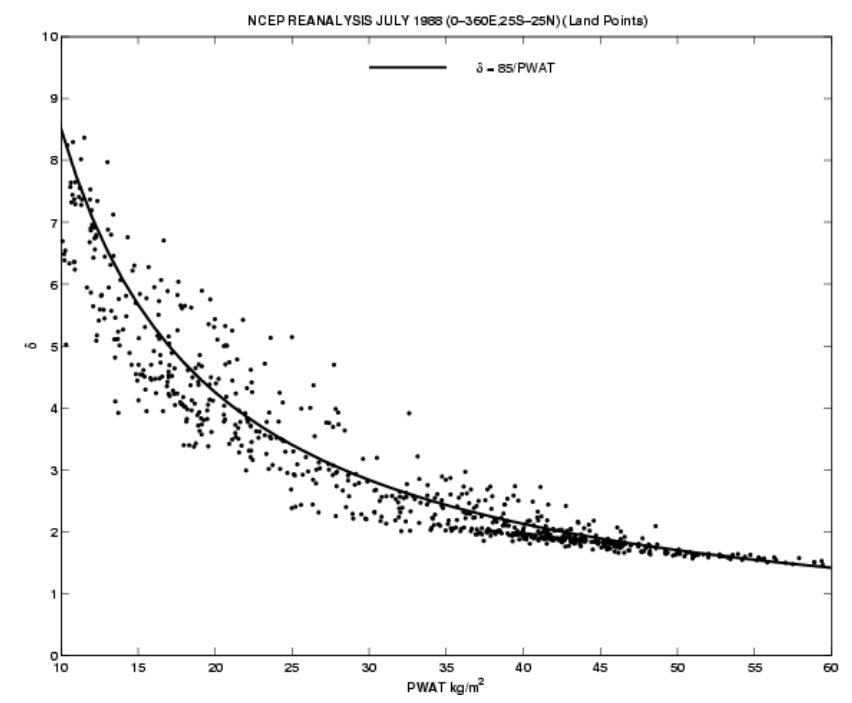

Fig. 1. Variation of the stability parameter $\delta$ with integrated water vapour in July 1988 based on data from NCEP reanalyses (Kalnay et al., 1996). Solid line corresponds to the curve $\delta=85 / P_{w}$.

water vapour and water vapor scale height. Note that the expression for $\delta$ does not contain terms involving the magnitude of vertical velocity. This happens because the parameter $\omega_{m}$ appears both in the numerator and denominator in the expression for $\delta$. The parameter that controls the value of $\delta$ is the total water vapour content in a vertical column of the atmosphere, also known as integrated water vapour $\left(P_{w}\right)$. We have obtained the values of $P_{w}, \lambda, p_{o}, \beta$, and $\Gamma$ for every $2.5^{\circ}$ by $2.5^{\circ}$ grid from NCEP reanalyses (Kalnay et al., 1996) and hence, calculated the value of $\delta$ from Eqs. (8) and (9). The variation of $\delta$ with $P_{w}$ is shown in Fig. 1 for tropical land regions in July 1988 . Note that at low $P_{w}$, there is a lot of scatter but for $P_{w}$ higher than $40 \mathrm{~kg} / \mathrm{m}^{2}$, the value of $\delta$ can be approximated quite well by the equation $\delta=85 / P_{w}$ (solid line in Fig. 1). The approximation $\delta=85 / P_{w}$ may not be accurate at low $P_{w}$ but it will not lead to large errors in the estimation of rainfall. This is because $\delta$ is large at low $P_{w}$ and hence, the second term in Eq. (4) is small compared to evaporation. Hence, Eq. (4) can be simplified further by using Eq. (9) and we obtain

$$
P=E+Q_{\text {net }} /\left\{C / P_{w}-1\right\}
$$

The value for $C$ in the above equation can be obtained from Eq. (9) but it may not be accurate. This is due to the simple assumptions we have made regarding the nature of variation of vertical velocity, temperature and specific humidity. The above assumptions were made to ascertain the important parameters on which $\delta$ depends. Since we have established the fact that $\delta$ can be expressed as $C / P_{w}$, we will now treat $C$ as an empirical constant which will be adjusted so that rainfall estimated from the simple model agrees well with the observed rainfall (or GCM rainfall in Sect. 3) The monthly mean precipitation can be estimated using Eq. (11), if the three parameters in the right-hand side of that equation can be estimated accurately. They are evaporation $(E)$, net radiation at the top of the atmosphere $\left(Q_{\text {net }}\right)$ and vertically integrated water vapor $\left(P_{w}\right)$. The net radiation at the top of the atmosphere was measured accurately during the Earth Radiation Budget Experiment (ERBE). This data is available on $2.5^{\circ}$ by $2.5^{\circ}$ grids for the period 1985-1989 (Barkstrom et al., 1989). The other two quantities can be estimated from the National Centre for Enviromental Prediction (NCEP) reanalyses (Kalnay et al., 1996). In Fig. 2, the seasonal variation of precipitation (in large tropical continents) estimated from Eq. (11) is shown (with $C=85$ ). This estimate has been compared with observations obtained from Xie and Arkin (1997). We find that the simple thermodynamic model proposed is able to simulate the seasonal variation of rainfall in tropical regions quite well. According to Neelin and Held (1987) the simple model proposed here should work well during the wet season but not during the dry season. The simple vertical structure assumed in the model will not be accurate in regions of descent. We find, however, that the simple model simulates the seasonal cycle of rainfall well, although the percentage error in rainfall simulated by the model is larger during the dry season. We illustrate the use of this simple diagnostic model in the next section. We use this model to identify the factors that contribute to the poor simulation of seasonal variation of rainfall in General Circulation Models.

\section{Errors in rainfall in AMIP II simulations}

We have examined the errors in precipitation in the following three GCM that participated in AMIP II. The GCM simulations we have considered are NCEP (National Center for Environmental Prediction), NCAR (National Center for Atmospheric Research) and JMA (Japan Meteorological Agency). We obtained the monthly mean rainfall, integrated water vapour, evaporation and net radiation at the top of the atmosphere simulated by these models during the period 1979 to 1995. The root mean-square (RMS) error in the simulation of monthly mean rainfall by GCM in large tropical continents was calculated for the period 1979-1995 (Fig. 3). The monthly mean rainfall was first averaged over the continental region before calculating the RMS error. All the 204 months were used to calculate the RMS error. The observed monthly mean rainfall was obtained from Xie and Arkin (1997). We find that the RMS error in NCEP exceeds $2 \mathrm{~mm} /$ day over India and South Africa, while in NCAR it exceeds $2 \mathrm{~mm}$ /day over North Africa and South America. The error in JMA is lower than the other two GCM in all tropical continents. To ascertain the reasons for the large errors in some GCM we have used the simple diagnostic model presented in Sect. 2.

We have used Eq. (11) to estimate the rainfall in tropical continents in these GCM based on the values of evaporation, net radiation and integrated water vapour in these models. We adjusted the value of $C$ for each model and in each region until the root mean-square difference between the rainfall estimated from the simple model and that simulated by 


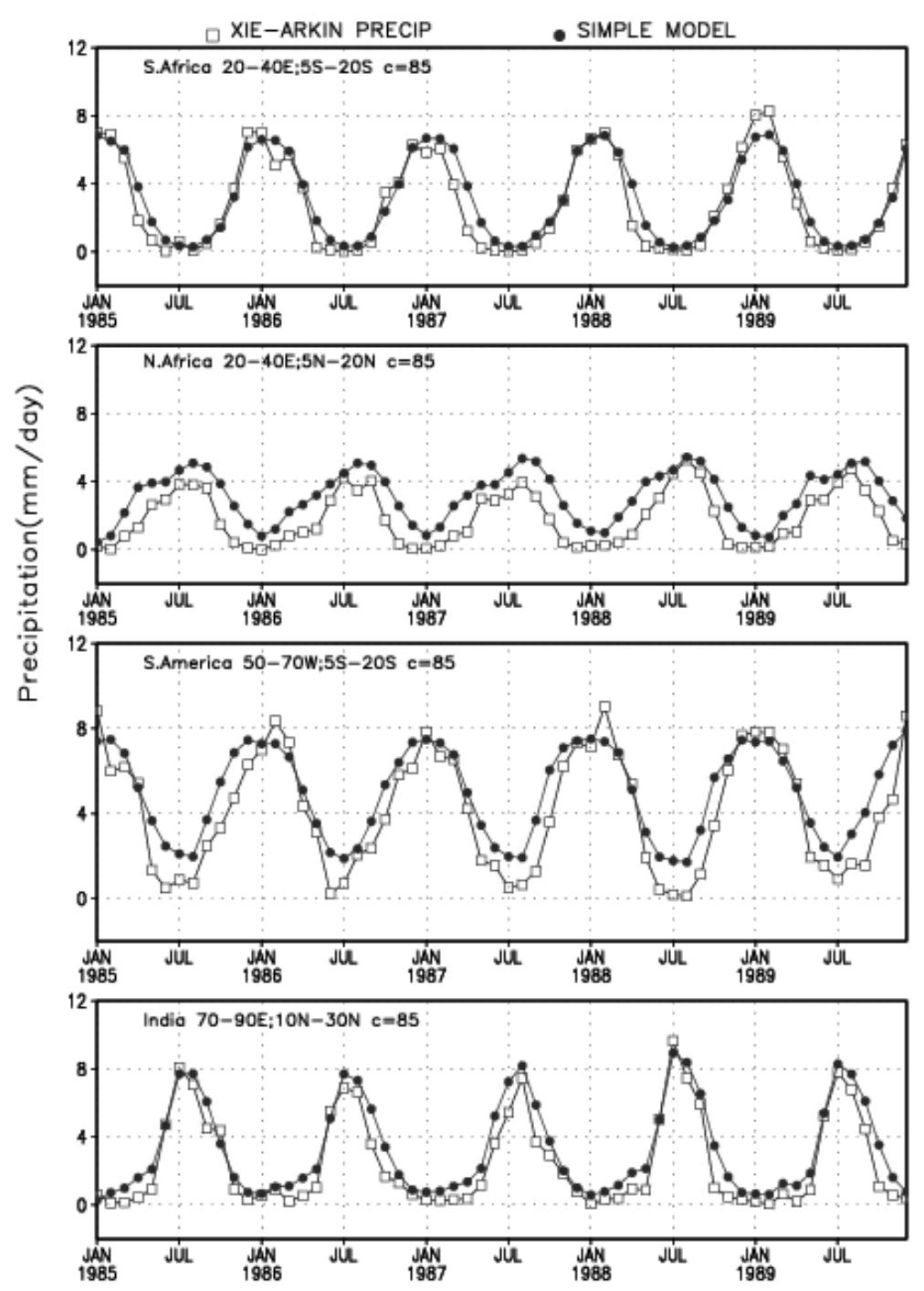

Fig. 2. Seasonal variation of precipitation in large tropical continents from the simple model (Eq. (11) and observations (Xie and Arkin, 1997) during 1985-1989.

Table 1. Value of constant $\mathrm{c}$ in different regions in different general circulation models

\begin{tabular}{lllll}
\hline Model & India & S. America & S. Africa & N. Africa \\
\hline NCEP & 65 & 75 & 60 & 60 \\
NCAR & 70 & 70 & 60 & 70 \\
JMA & 85 & 80 & 60 & 70 \\
\hline
\end{tabular}

GCM was a minimum (see Table 1). In Fig. 4, the seasonal variation of rainfall over India in the three GCM is shown, along with the estimate from the simple model. Note that the value of $C$ used in different GCM is quite different. In the Indian region the value of $C$ in JMA is 85 (which is the same as that obtained in the last section from the NCEP reanalyses) while the value of $C$ in NCEP and NCAR is much lower than 85 . Note that the interannual variation of rainfall in NCEP is much larger than either JMA or NCAR. We find that the simple model is able to capture the seasonal variation of rainfall in the GCM quite well, although we find the errors are greater than $2 \mathrm{~mm}$ /day on a few occasions. This suggests that this simple model will be useful to examine why there are large errors in the rainfall simulated by the GCM in certain regions and in certain seasons.

The error in the simulation of rainfall by a GCM could be due to errors in the simulation of evaporation, net radiation, integrated water vapour or the value $C$. Hence, we have calculated the root mean-square error in integrated water vapour, evaporation, and net radiation in the three GCM in different regions. The root mean-square errors in integrated water vapour and evaporation in these models were calculated with data from NCEP reanalyses that were assumed to represent true observations. It is not easy to estimate the errors in the simulation of net radiation during the period 1979 to 1995 , since the net radiation in NCEP reanalyses data is 

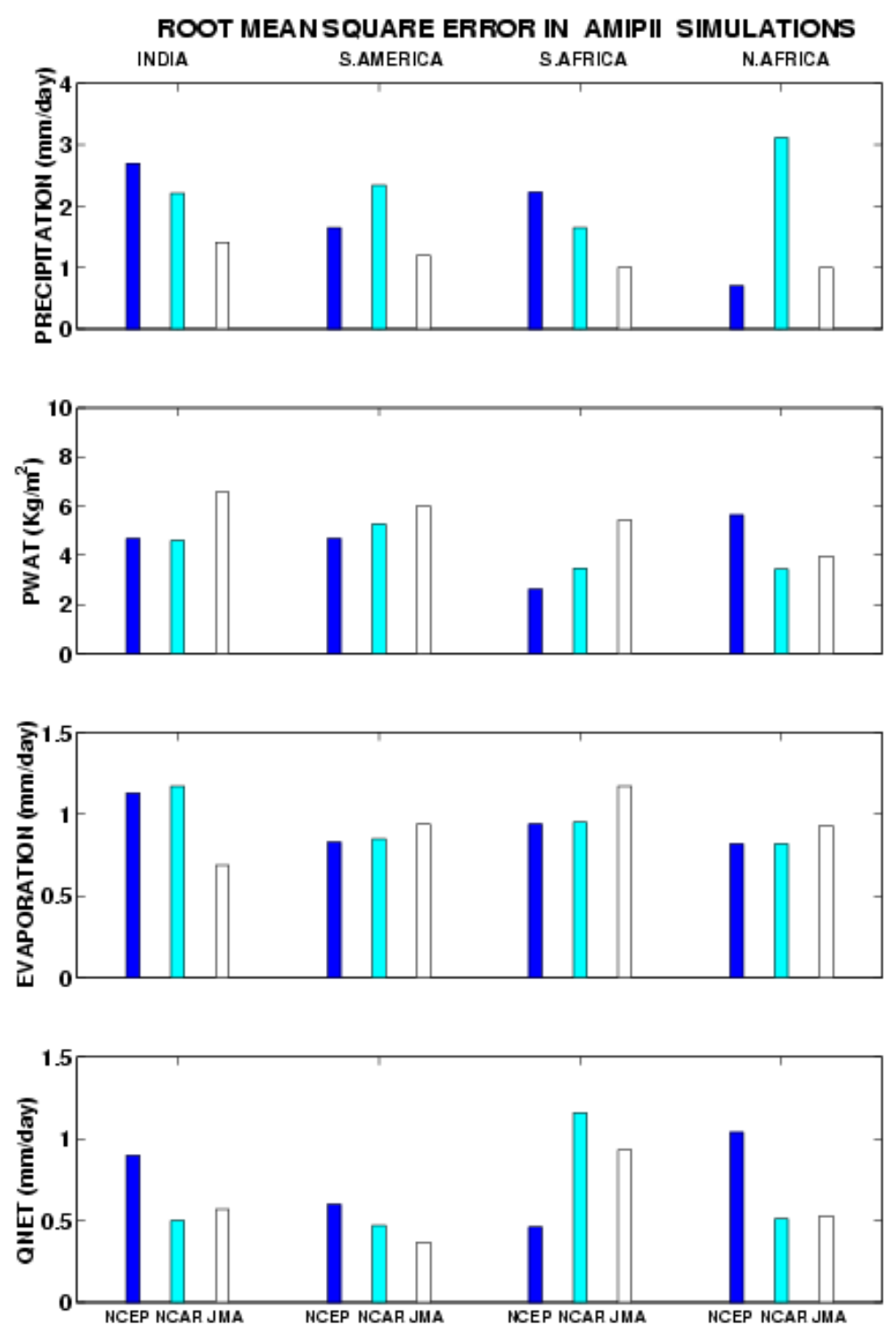

Fig. 3. Root mean-square error in rainfall, integrated water vapour, net radiation, and evaporation in NCEP, NCAR and JMA GCM in different continental regions.

known to have a large bias (Weare, 1997). We have, therefore, used the data from the Earth Radiation Budget Experiment (ERBE) for the period 1985-1989. Note that the RMS error in integrated water vapour and evaporation (Fig. 3) is not the highest in the NCAR and NCEP models in regions where their RMS error in simulated rainfall is the highest. In India, South America and South Africa the RMS error in integrated water vapour is the highest in JMA, although its root mean-square error in rainfall is the lowest in these regions! RMS error in evaporation in all three GCM is similar and around $1 \mathrm{~mm} /$ day. The RMS error in net radiation is around 1 mm/day in all three GCM during 1985-1989 (Fig. 3). Hence, the errors in the simulation of evaporation, integrated water vapour or net radiation alone cannot be the primary reason for the high RMS errors in the NCEP and NCAR models. We must conclude, therefore, that the value of $C$ (which is dependent upon the vertical profile of temperature and humidity) must play an important role in GCM wherein the RMS error in rainfall is high.

Note that the value of $C$ in NCEP and NCAR is much lower than that in JMA. In the last section, we found that the rainfall estimated by the simple model agrees well with observations when the observed values of net radiation, evaporation and integrated water vapour were used and $C$ was set equal to 85. Among the General Circulation models considered here, JMA has a value of $C$ around 85 , while in NCAR and NCEP the value of $C$ is much lower than 85 . To demonstrate that the large error in the NCEP is primarily due to the low value of $C$, we have examined the seasonal variation in rainfall over India in NCEP in 1995 and 1998. In both of these years the rainfall simulated by NCEP was much larger than the observations. In Fig. 5, we have compared the 

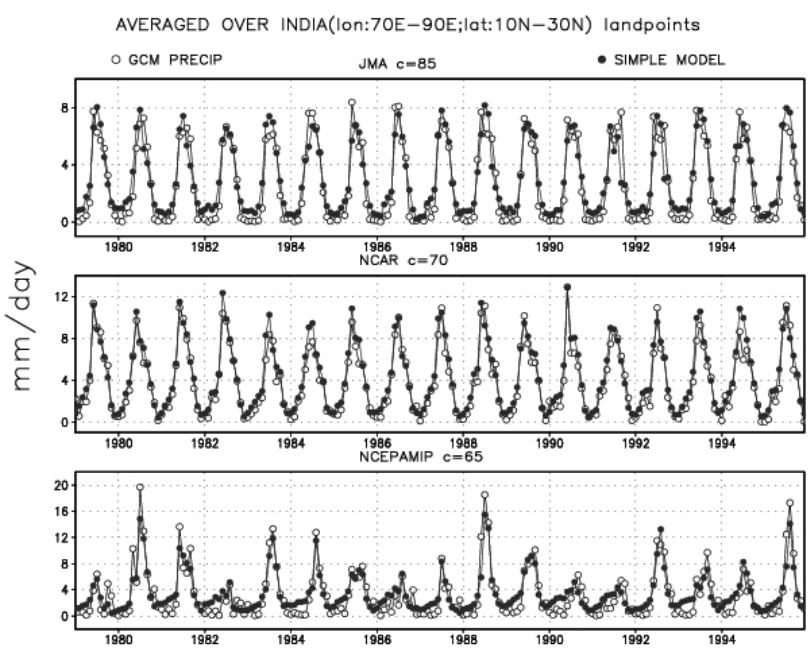

Fig. 4. Seasonal variation of precipitation over India in NCEP, NCAR and JMA GCM and simple model (Eq. 10) during 19791995.

seasonal variation of rainfall over India in NCEP with observations in 1988 and 1995. We have shown, in addition, the rainfall simulated by the simple model using NCEP values of evaporation, net radiation and integrated water vapour. We have shown the results for two values of $C$ (i.e. 65 and $85)$. The seasonal variation of rainfall in the simple model is closer to NCEP when $C=65$ and closer to the observations when $C=85$. Note that the large error in rainfall NCEP is reduced when we use $C=85$. This shows that errors in net radiation, integrated water vapour or evaporation are less important than the error in $C$ in NCEP. Hence, the large error in the simulation of rainfall in NCEP in 1988 and 1995 due to the low value of $C$ in NCEP. This establishes clearly the fact that $C$ is an important parameter in regions such as India where $P_{w}$ approaches $C$.

\section{Role of nonlinearity}

An interesting feature of Eq. (11) is that precipitation is a nonlinear function of $P_{w}$ for large $P_{w}$. The highest value of $P_{w}$ occurs in the Indian region during the monsoon and in July the value of $P_{w}$ can be above $50 \mathrm{~kg} / \mathrm{m}^{2}$. Hence, the nonlinearity in Eq. (11) will manifest itself in the Indian region since $P_{w}$ approaches $C$. This nonlinearily will not manifest itself strongly in JMA because $C=85$ in that model but it can occur in NCEP wherein $C=65$. This can be seen clearly in the relationship between monthly mean rainfall and $P_{w}$ in both GCM and observations. The monthly mean rainfall is shown as a function of $P_{w}$ over the Indian region in Fig. 6. We find the JMA is closer to observations when compared to either NCAR or NCEP.

The impact of change in $P_{w}$ on rainfall can be derived from Eq. (11) and expressed as follows:

$$
\Delta P=\Delta P_{w}\left\{Q_{\mathrm{net}} C /\left[C-P_{w}\right]^{2}\right\}
$$
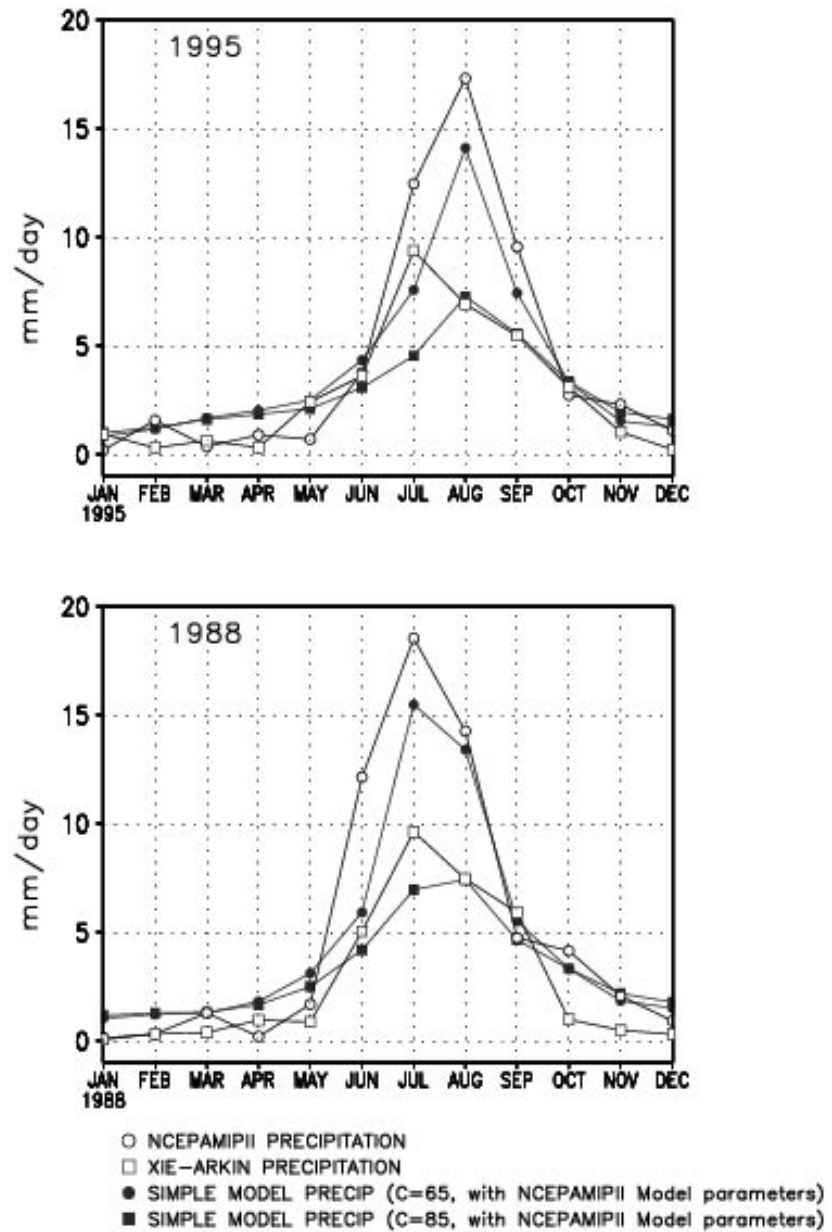

Fig. 5. Seasonal variation of rainfall over India in NCEP GCM in 1988 and 1995.

where $\Delta P$ is the change in rainfall due to a change in $P_{w}$ $\left(\Delta P_{w}\right)$.

From the above equation we see that when $P_{w}$ is $50 \mathrm{~kg} / \mathrm{m}^{2}$ and $Q_{\text {net }}$ is $3 \mathrm{~mm} /$ day and $C=85$, a change (or error) in $P_{w}$ of $10 \mathrm{~kg} / \mathrm{m}^{2}$ will cause a change (or error) in rainfall of $1.2 \mathrm{~mm} /$ day. On the other hand, if $C=65$ with the same values of $Q_{\text {net }}$ and $P_{w}$, a change (or error) in $P_{w}$ of $10 \mathrm{~kg} / \mathrm{m}^{2}$ will cause a change (or error) in rainfall of $6.67 \mathrm{~mm} /$ day. In other words, the rate of change in rainfall with $P_{w}$ is about five times larger when $C=65$ as compared to the case with $C=85$. Note the extremely high rainfall in NCEP GCM when $P_{w}$ exceeds $50 \mathrm{~kg} / \mathrm{m}^{2}$. The value of $P_{w}$ in JMA exceeds $55 \mathrm{~kg} / \mathrm{m}^{2}$ on some occasions but this does not lead to an overestimation of rainfall because $C=85$ in this model. On the other hand, in the NCEP, the simulated rainfall exceeds the observation even though the value of $P_{w}$ simulated by this model is realistic and does not exceed $55 \mathrm{~kg} / \mathrm{m}^{2}$. This is due to the low value of $C$ in the NCEP and hence, $C / P_{w}$ tends towards 1 earlier in this GCM than in JMA. The interannual variation of rainfall will also be large when $C / P_{w}$ approaches 1 . The inter-annual standard deviation of monthly mean rainfall (based on all the 204 months) in tropical con- 


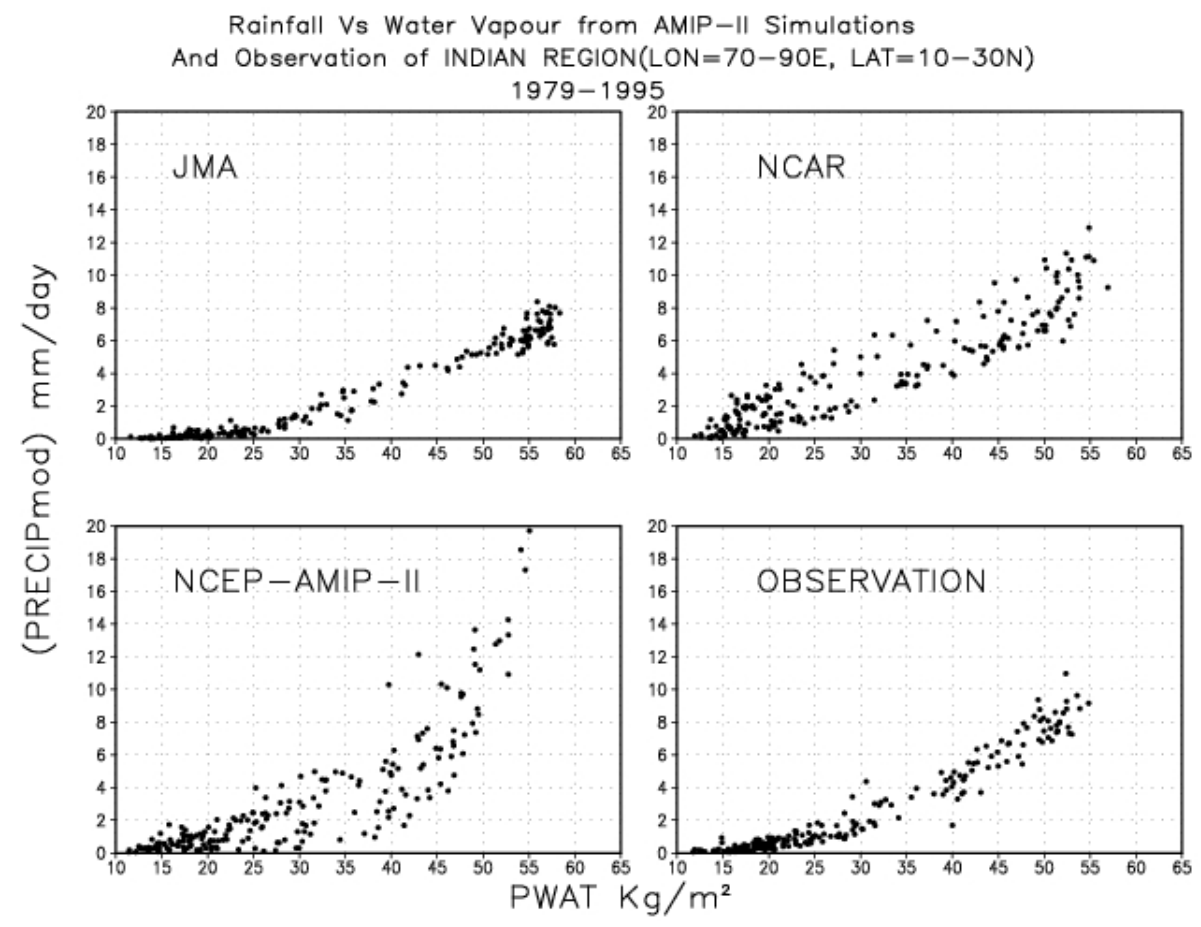

Fig. 6. Relationship between rainfall and integrated water vapour over India in NCEP, NCAR and JMA GCM and observations during 1979-1995.

tinents is shown in Fig. 7. We find that the interannual standard deviation of rainfall in NCEP is unusually large, while in JMA the values are closer to the observations. This is because the value of $C$ in JMA is close to the observations, while the value of $C$ in NCEP is much smaller than the observations.

Why is $C$ lower in NCEP and NCAR than JMA? According to Eq. (10), $C$ depends upon the temperature lapse rate $(\Gamma)$ and the non-dimensional exponent $(\lambda)$. The value of $\lambda$ depends upon the water-vapour scale height. If $\lambda$ is small, then the upper troposphere is more moist, while if $\lambda$ is large, the upper troposphere is drier. We can calculate $\lambda$ if we know $P_{w}$ and the surface specific humidity $q_{o}$. In Fig. 8, we have shown the value of $\lambda$ in the three GCM in July (India and North Africa) and in January (South Africa and South America). We find that the value of $\lambda$ is the lowest in JMA and the highest in NCEP. From Eq. (10) we find that $C$ has the following variation with $\lambda$

$C \sim(\lambda+2) / \lambda$.

We find that in the JMA $\lambda$ is between 2 and 2.5 , while in the NCEP it is between 3 and 4.5. The above equation would indicate that if the value $C$ in JMA is 85 , then the value of $C$ in NCEP should be around 68 . This is close to the value of $C$ for NCEP that was obtained empirically in Sect. 3 by ensuring that the root mean-square difference in rainfall between the simple model and GCM was a minimum. Hence, we conclude that the value of $C$ is different in different GCM, primarily because of the variations in $\lambda$. The errors in NCEP and NCAR may reduce if the value of $\lambda$ is decreased by ensuring that more moisture is pumped into the higher layers in the troposphere. This depends on the manner in which the vertical transport of moisture is treated in the GCM. Nanjundiah (2000) has shown that the vertical profile of moisture in NCAR changes substantially when the moisture transport formulation is changed from the spectral method to the semiLagrangian method.

In regions such as Africa where $P_{w}$ is small, other parameters in Eq. (11) will contribute to errors in the simulation of rainfall. For example, the root mean-square error in the rainfall simulated by NCAR is very large in North Africa. In Fig. 9, the error in GCM rainfall (compared with observations from Xie and Arkin, 1997) is shown as a function of error in net radiation at the top of the atmosphere (compared to ERBE data) in North Africa. The error in rainfall simulated by NCAR in North Africa is large because the error in net radiation simulated by this GCM is large. Note that NCEP underestimates the net radiation in North Africa but it did not induce large errors in the simulation of rainfall. This is because in the NCEP simulation the lower $Q_{\text {net }}$ was partly compensated due to the low value of $C$ in this GCM (see Table 1). This compensation did not take place in NCAR. This indicates that an accurate simulation of rainfall in a GCM need not necessarily be due to an accurate estimate of evaporation, net radiation, integrated water vapour or $C$. In the NCEP the errors in rainfall in North Africa were lower than NCAR due to the compensation between errors in $Q_{\text {net }}$ and $C$. In NCEP, $Q_{\text {net }}$ is lower than ERBE observations in all tropical continents. If the radiation code in this GCM is modified to reduce this error, it may actually increase the error in rainfall because of the low value of $C$ in this GCM. 

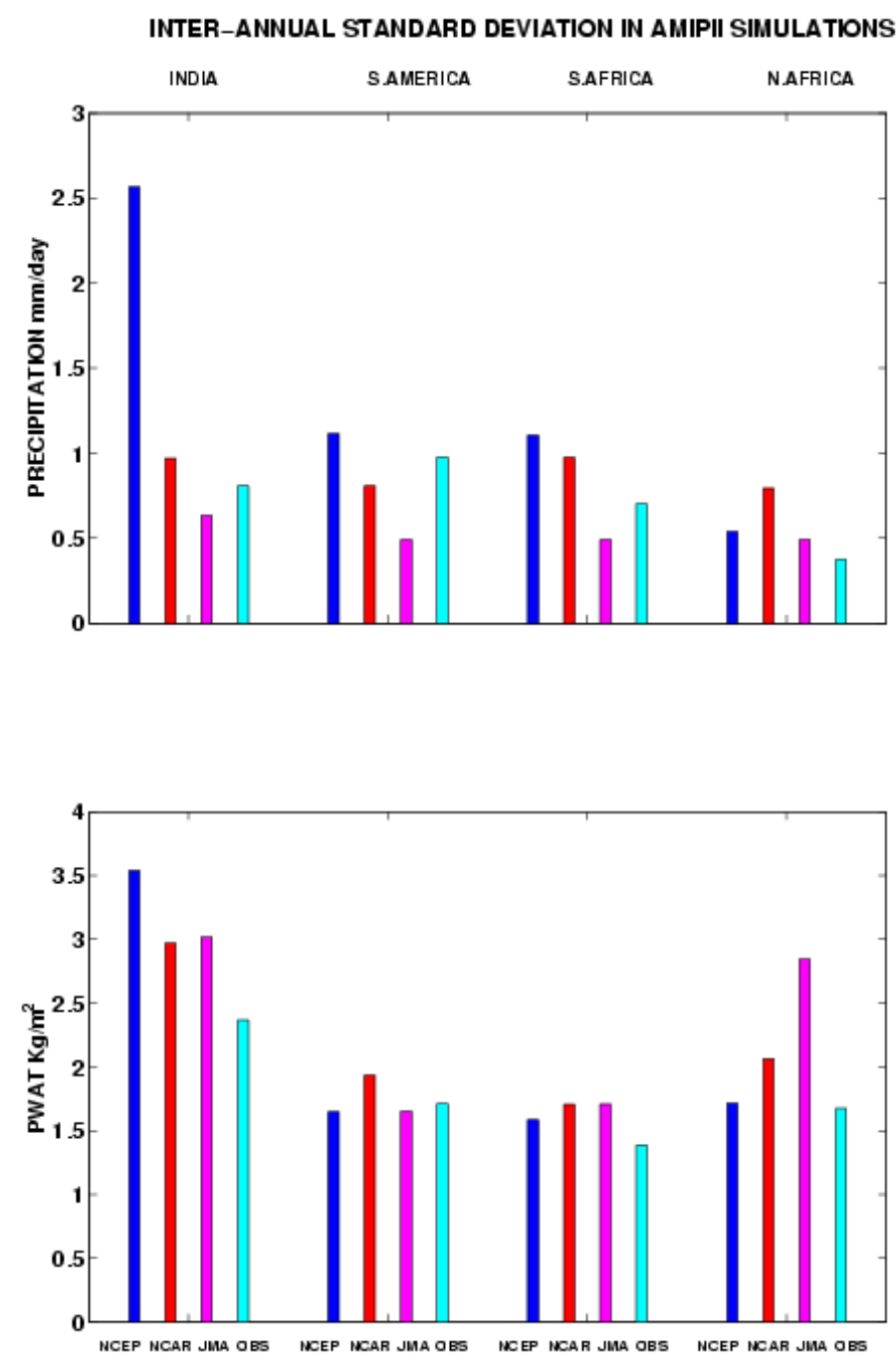

Fig. 7. Interannual standard deviation of monthly mean rainfall and integrated water vapour in NCEP, NCAR and JMA GCM.

\section{Interaction between different errors}

The error in the simulation of rainfall in a GCM is due to errors in the simulation of evaporation, net radiation, integrated water vapour and the parameter $C$. Since errors can either combine or compensate, it will be useful to examine the combined effect of all these errors, which can be derived from Eq. (11) and expressed as follows:

$$
\begin{aligned}
\Delta P & =\Delta E+(P-E)\left\{\Delta Q_{\text {net }} / Q_{\text {net }}\right. \\
& \left.+\Delta P_{w} / P_{w}+\Delta P_{w} /\left[C-P_{w}\right]-\Delta C /\left[C-P_{w}\right]\right\}
\end{aligned}
$$

$$
\begin{array}{ll}
\Delta P & =\text { Estimated error in rainfall } \\
\Delta E & =\text { Error in evaporation }=E_{\text {model }}-E_{\text {obs }} \\
\Delta Q_{\text {net }} & =\text { Error in net radiation }=Q_{\text {net }}(\text { model })- \\
& Q_{\text {net }}(\text { ERBE }) \\
\Delta P_{w} \quad & =\text { Error in integrated water vapour }= \\
& P_{w}(\text { model })-P_{w}(\text { NCEP reanalyes }) \\
\Delta C \quad & =\text { Error in } C=C(\text { model })-C(\text { NCEP reana- } \\
& \text { lyes })
\end{array}
$$

Note that if the errors $Q_{\text {net }}$ and $P_{w}$ are of the same sign they add up, while if they are of the opposite sign, they can cancel. In NCEP and NCAR the dominant contribution in the above equation comes from the term last term in the righthand side of the equation, since the error in $C$ is much larger than the error in $Q_{\text {net }}$ or $P_{w}$. In NCEP and NCAR, $\Delta C$ is negative and hence, these models tend to overestimate rainfall. In North Africa, the root mean-square error in rainfall is low in NCEP because $\Delta Q_{\text {net }}$ and $\Delta P_{w}$ are both negative and hence, they partly cancel out the large positive contribution from the last term (i.e. $\left.-\Delta C /\left(C-P_{w}\right)\right)$. This does not happen in NCAR in North Africa because $\Delta Q_{\text {net }}$ and $\Delta P_{w}$ are both positive and hence, they add to the large positive contribution from the last term (i.e. $\left.-\Delta C /\left(C-P_{w}\right)\right)$.

We compare the actual error in the simulation rainfall in a GCM with the error estimated from the simple model. The estimated error in rainfall is

$$
\begin{aligned}
& \Delta P_{\text {est }}=\left[E_{\text {model }}-E_{\text {obs }}\right]+\left\{\left[Q_{\text {net }} /\left(C / P_{w}-1\right)\right]_{\text {model }}\right. \\
& -\left[Q_{\text {net }} /\left(C / P_{w}-1\right)\right]_{\mathrm{obs}} .
\end{aligned}
$$




\section{$\lambda$ IN AMIP I| MODELS}
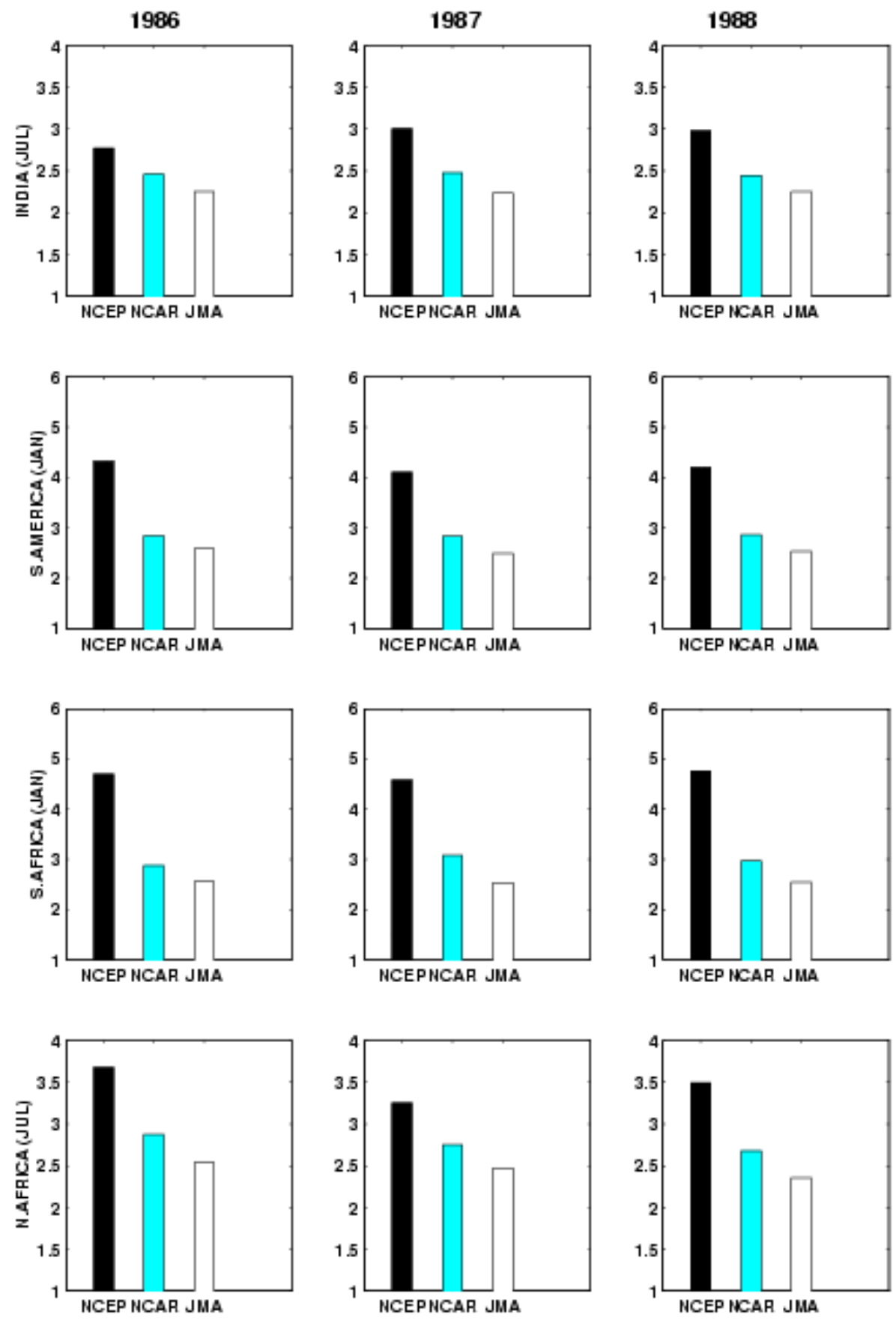

Fig. 8. Variation of non-dimensional water vapour scale height $\lambda$ in different GCM.

The actual error in rainfall is defined as the difference between GCM rainfall and the rainfall obtained from Xie and Arkin (1997). In Fig. 10, we have compared the actual error in the simulation of rainfall in NCAR with the estimated error in rainfall (Eq. 15) in the Indian region. We have also shown the error in $Q_{\text {net }}, P_{w}$ and $E$. The estimated error in rainfall shows the same trend as the actual error in rainfall. There are six occasions when the NCAR overestimates the rainfall by more than $4 \mathrm{~mm} /$ day. In all of these cases the $P_{w}$ in the model was at least $6 \mathrm{~kg} / \mathrm{m}^{2}$ higher than the observations. In most of these cases the model evaporation was 2 $\mathrm{mm}$ /day higher than the observations. Hence, the errors in $P_{w}$ and evaporation were the main reasons for the overestimation of rainfall by NCAR. Note that the NCAR tends to underestimate $Q_{\text {net }}$. If this had not occurred, the errors in rainfall in NCAR may have been even higher. The error in the simulation of rainfall in a GCM is often been attributed to a single factor such as the cumulus scheme. The present 


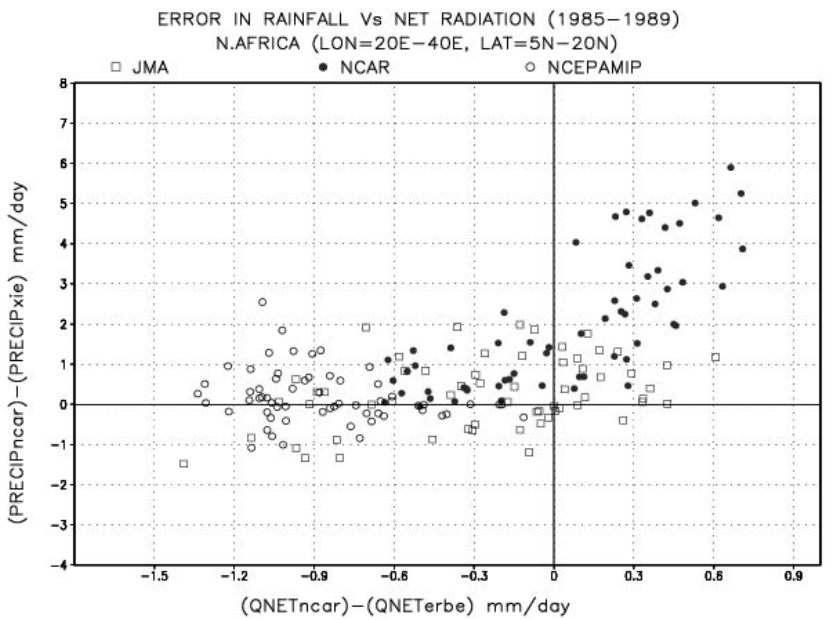

Fig. 9. Relationship between error in rainfall and error in net radiation in North Africa.

work shows that a combination of factors can contribute to large errors in the simulation of tropical rainfall. In Fig. 11 we have compared the actual error in the simulation of rainfall in JMA with the estimated error in rainfall (Eq. 15) in South America. This figure shows that the error in rainfall in JMA is low, although the error in parameters, such as $P_{w}$ and $E$ are quite large. We find that when the error in $P_{w}$ is large and positive, the error in evaporation is large and negative. In JMA, errors in $P_{w}$ and $E$ are of opposite sign and hence, there is compensation (see Eq. 15).

\section{Conclusions}

We have used a simple diagnostic model for tropical precipitation to identify the factors that contribute to errors in the simulation of rainfall in tropical continents in Atmospheric General Circulation Models (GCM). The four basic parameters that contribute to errors in the simulation of rainfall are evaporation, net radiation, integrated water vapour and $C$ (which depends on the vertical profile of temperature and moisture). The errors in the simulation of these parameters can arise due to errors in the parameterization of cumulus convection, cloud radiative properties or boundary layer processes. We have shown that the large errors in the simulation of rainfall in the Indian region in NCEP was because the value of $C$ in this model was much lower than 85 . The low value of $C$ caused a large interannual variation of rainfall in the Indian region because $C / P_{w}$ approached 1 in this region. The value of $C$ depends primarily upon the vertical profile of moisture in the GCM. Hence, more attention is needed to understand what factors contribute to errors in the simulation of the vertical profile of moisture. The vertical profile of moisture in a GCM is sensitive to the manner in which moisture transport is numerically modeled (Nanjundiah, 2000). The inability of many GCM to simulate the Indian monsoon rainfall has been attributed to orography or inadequate spatial resolution. Although these factors could be important, the
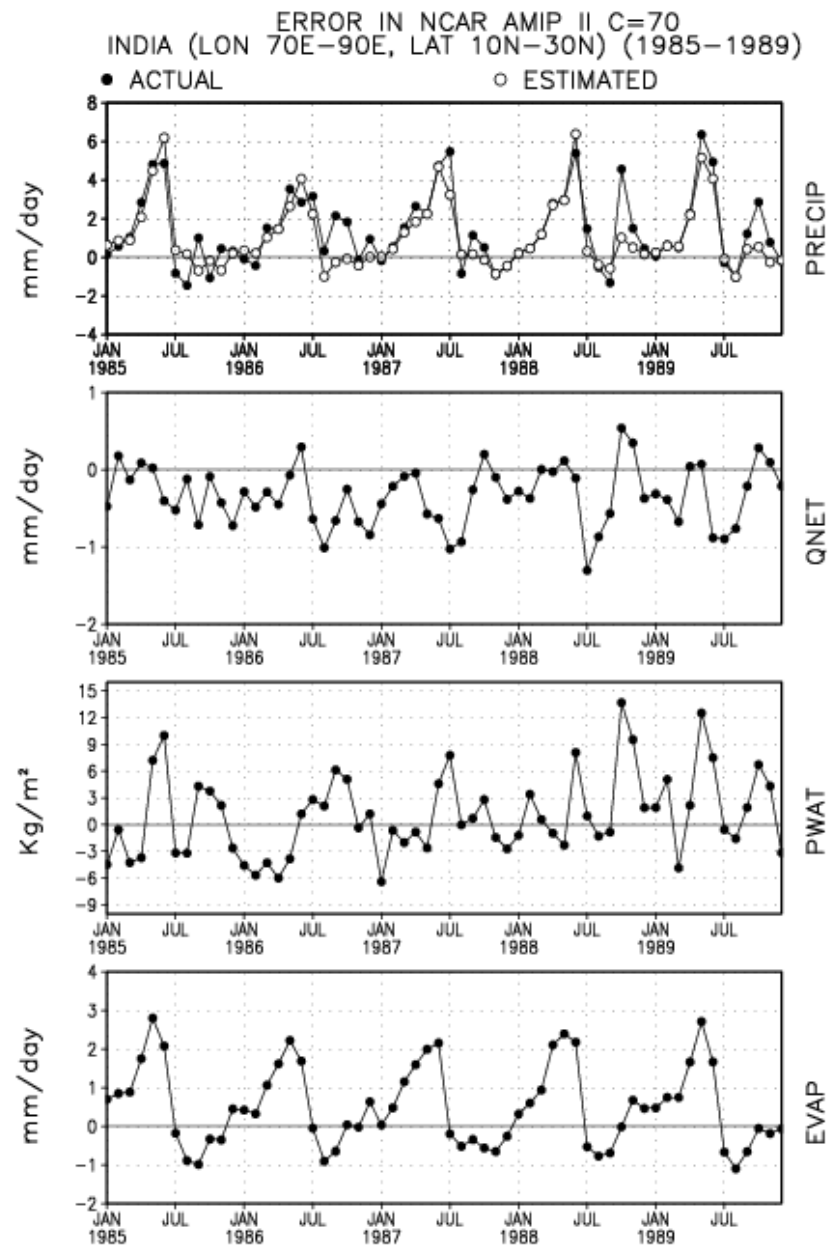

Fig. 10. Comparison between actual error in rainfall in NCAR GCM and the error in rainfall estimated from the simple model in the Indian region. Errors in $Q_{\text {net }}, P_{w}$ and evaporation have also been shown.

present paper highlights the fact that an unusual singularity exists in the Indian region because $C / P_{w}$ approaches 1 in this region. This can contribute to large errors in the simulation of seasonal and interannual variation of rainfall. The poor simulation seasonal variation of rainfall in NCAR in North Africa was due to errors in the simulation of net radiation. The low errors in the simulation of rainfall in JMA was due to the cancellation of errors in $P_{w}$, evaporation and because the value of $C$ in this model was close to the observations.

The diagnostic model discussed in this paper was useful in understanding the factors that contribute to errors in the simulation of monthly mean rainfall in large tropical continents. The model was also able to explain why the interannual variability of rainfall was high in NCEP. The simple diagnostic model will not be useful in understanding the interannual variation of rainfall in JMA or NCAR because of the low interannual variability of rainfall in these models. When the interannual variability of rainfall is low, the neglect of horizontal advection terms in Eqs. (1) and (2) cannot be justified. 


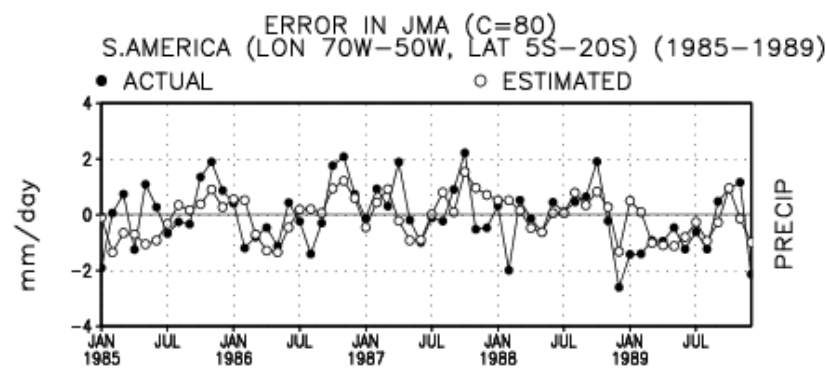

USA and the modeling groups for providing the data from AMIP II simulations. This work was supported by Department of Science and Technology, New Delhi and Indian Space Research Organization, Bangalore. Prof. Sulochana Gadgil made several useful suggestions to improve the manuscript. I thank Vidyunmala, Asha, and Anoop for their assistance in the analysis of data.

Topical Editor O. Boucher thanks R. Roca and another referee for their help in evaluating this paper.
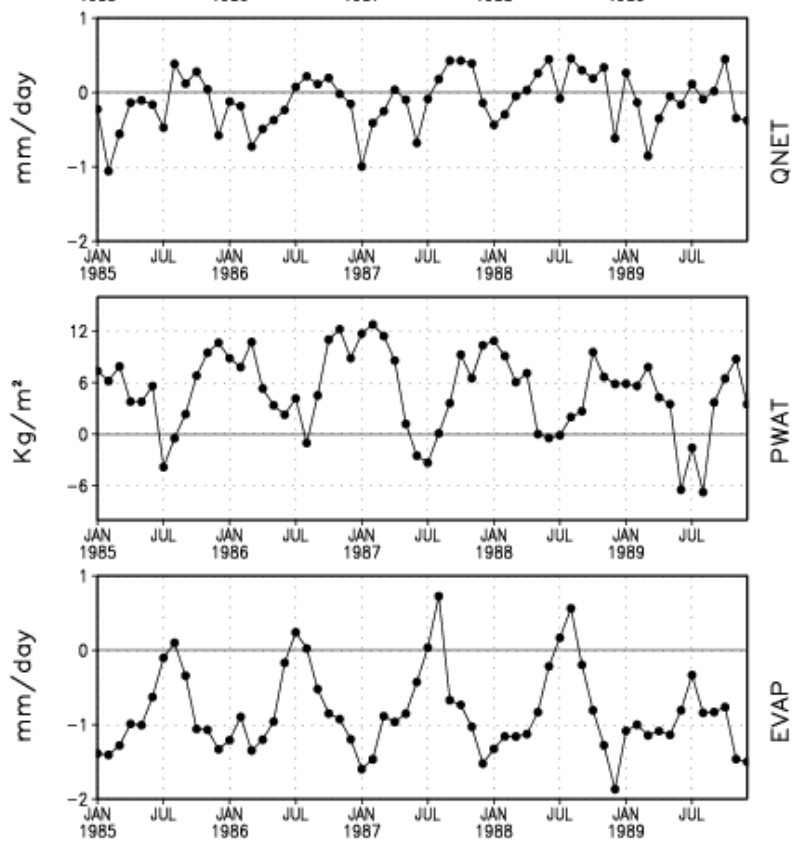

Fig. 11. Comparison between actual error in rainfall in JMA GCM and the error in rainfall estimated from the simple model in South America. Errors in $Q_{\text {net }}, P_{w}$ and evaporation have also been shown.

Acknowledgements. This work was done as a part of the AMIP diagnostic subproject on "Monsoon Precipitation". We thank the entire AMIP team in the Program for Climate Model Diagnosis and Inter-comparison at Lawrence Livermore National Laboratory,

\section{References}

Barkstrom, B. R., Harrison, E., Smith, G., Green, R., Kibler, J., Cess, R., and ERBE Science Team: Earth Radiation Budget Experiment(ERBE) archival and April 1985 results, Bull. Amer. Meteor. Soc., 70, 1254-1262, 1989.

Fortelius, C. and Holopainen, E.: Comparison of energy source estimates derived from atmospheric circulation data with satellite measurements of net radiation, J. Clim, 3, 646-660, 1990.

Gadgil, S. and Sajani, S.: Monsoon Precipitation in the AMIP runs, Climate Dyn., 14, 659-689, 1998.

Gates, W. L.: AMIP: the Atmospheric Model Inter-comparison Project, Bull. Am. Meteorol. Soc., 73, 1962-1970, 1992.

Kalnay, E., Kanamitsu, M., Kistler, R., Collins, W., Deaven, D., Gandin, L., Iredell, M., Saha, S., White, G., Woollen, J., Zhu, Y., Chelliah, M., Ebisuzaki, W., Higgins, W., Janowiak, J., Mo, K. C., Ropelewski, C., Wang, J., Leetmaa, A., Reynolds, R., Jenne, R., and Joseph, D.: The NCEP/NCAR 40-year reanalysis project, Bull. Am. Meteorol. Soc., 113, 2158-2172, 1996.

Nanjundiah, R. S.: Impact of the moisture transport formulation on the simulated tropical rainfall in a General Circulation Model, Climate Dyn., 16, 303-317, 2000.

Neelin, J. D. and Held, I. M.: Modeling Tropical Convergence based on the Moist Static Energy Budget, Mon. Weather Rev., 115, 3-12, 1987.

Srinivasan, J.: A simple Thermodynamic model for seasonal variation of monsoon rainfall, Current Science, 80, 73-77, 2001.

Weare, B. C.: Comparison of NCEP-NCAR cloud radiative forcing reanalyses with observations, J. Clim., 8, 2200-2209, 1997.

Xie, P. and Arkin, P. A.: Global Precipitation: A 17-year monthly analysis based on gauge observations, satellite estimates ad numerical model outputs, Bull. Am. Meteorol. Soc., 78, 25392558, 1997. 